\title{
COMUNICACÕES
}

\section{Alternaria alternata causing foliar blight on Chrysanthemum morifolium in Corrientes, Argentina}

\author{
Gauna Mónica Patricia ${ }^{1}$, Gutiérrez Susana Alejandra ${ }^{1}$, Bich Gustavo Angel ${ }^{2,3}$, Castrillo María Lorena ${ }^{2,3}$, Zapata Pedro \\ Dario $^{2,3}$, Cabrera María Graciela ${ }^{1}$
}

\begin{abstract}
${ }^{1}$ National University of Northeast, Faculty of Agricultural Sciences, Department of Vegetal Protection, Sargento Cabral 2131 CP3400, Corrientes, Argentina. ${ }^{2}$ Misiones Biotechnology Institute "Dra. María Ebe Reca". 12 Road, Km 7,5. CP 3300. Misiones, Argentina. ${ }^{3}$ Consejo Nacional de Investigaciones Científicas y Técnicas (CONICET).

Corresponding author: Gauna Mónica Patricia(monica_patricia_gauna@yahoo.com.ar)

Data de chegada: 14/11/2017. Aceito para publicação em: 28/11/2019.
\end{abstract}

$10.1590 / 0100-5405 / 187848$

In Corrientes, province of Argentina, Chrysanthemum morifolium Ramat (Asteraceae), is the second most important crop of cut flowers, following gladiolus. Chrysanthemum is a type of floral plants frequently affected by several diseases such as white rust (Puccinia horiana), withering (Fusarium sp. and Verticillium sp.), spots and foliar blight caused by Alternaria spp. and Septoria sp. (1). In Corrientes Province, this disease produces losses of $60 \%$ plants in greenhouses. Thus, new observations and studies have been conducted to get to know the species of Alternaria that is involved in the disease affecting chrysanthemum in Corrientes. Samples showing symptoms of foliar blight were collected from crops in Concepción and Corrientes Cities at different times of the year during the growing period (Fig. 1A).

The diseased plant material was washed in running tap water, surface disinfected with $10 \%$ sodium hypochlorite solution, and rinsed with distilled water. After surface disinfection, plant tissues were cut into small fragments, which were placed in plates containing potato-glucose-agar (PGA-2\% w/v, $\mathrm{pH}$ 6.6-7) for the development of fungal colonies under laboratory conditions of $12 \mathrm{~h}$ light- $12 \mathrm{~h}$ darkness photoperiod, at $25^{\circ} \mathrm{C}(3)$. After purification of strains through monosporic cultivation, the fungal colonies were preserved in test tubes with sloped PGA. The fungal isolate of interest, M5, was deposited in the culture collection of the Department of Plant Protection (National University of Northeast) and National University of Misiones, receiving the accession number LBM 212. The morphological characteristics were established considering the study of pure strains obtained from one spore of each isolated strain cultivated in PGA (2\%, pH $6.6-7)$. Cultural characteristics were recorded from the isolate cultivated in PGA, which was developed under conditions of $12 \mathrm{~h}$ light- $12 \mathrm{~h}$ darkness, at $25^{\circ} \mathrm{C}$. Furthermore, macroscopic characteristics of each developed fungal colony were described based on the observation of the following parameters: growth rate, aspect and top and bottom color of the colony. Microscopic features like characteristics of the mycelium, conidiophores and conidia were also analyzed for morphological identification under an Enosa optical microscope (400x), using fresh material from diseased leaves, stems and flowers mounted on sterile water.

Mycelia for DNA extraction were grown in liquid cultures at 28 $\pm 1^{\circ} \mathrm{C}$ in malt extract broth for molecular identification. Amplifications were confirmed by standard gel electrophoresis, using $2 \% \mathrm{w} / \mathrm{v}$ agarose gels (InBio, Argentina) in 0.5X TBE Buffer, and staining with Gel Red Solution (Biotium, 10000X). After amplification, the amplicons were
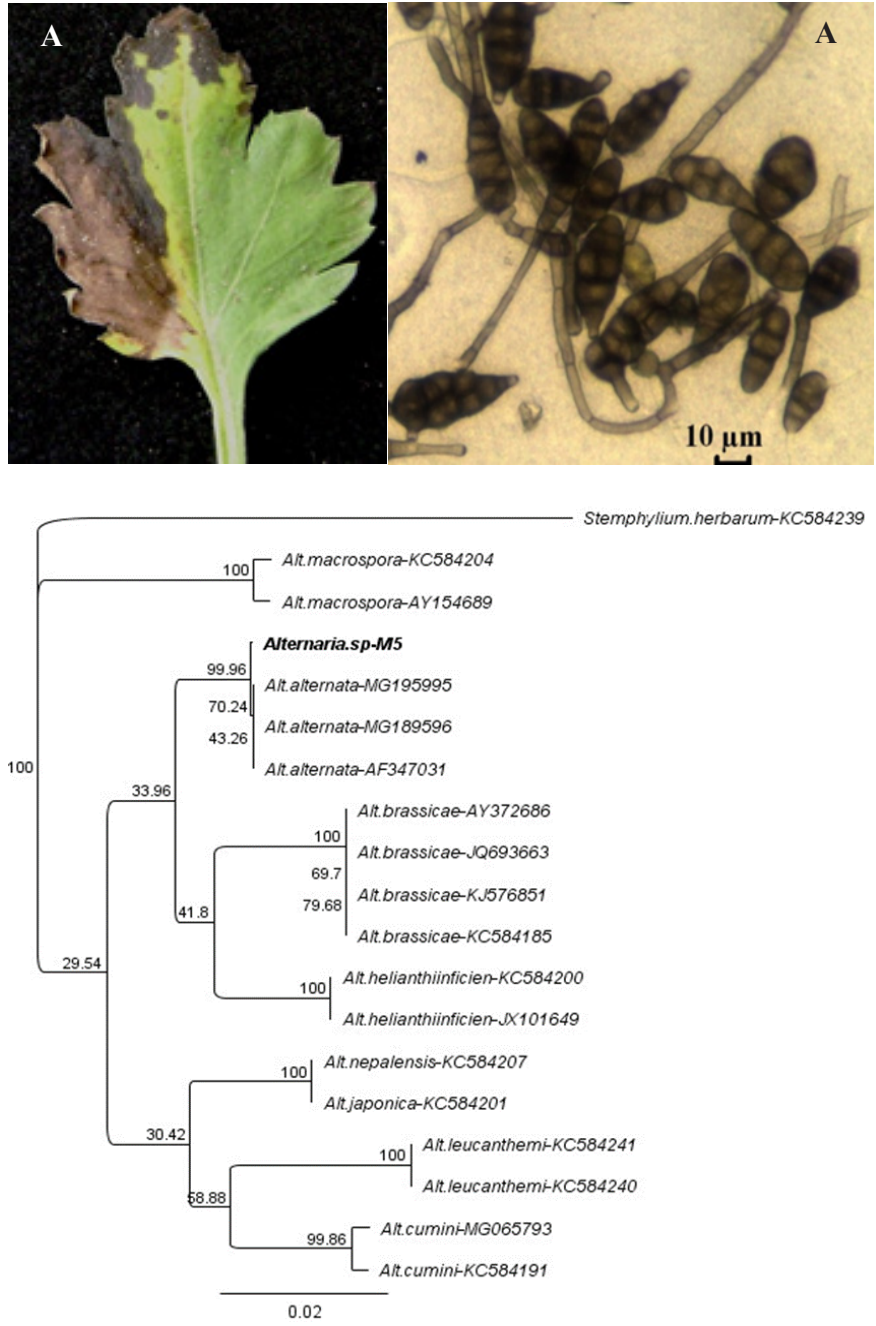

Figura 1. Symptoms of foliar blight on a fungal-inoculated chrysanthemum leaf (A); Conidial structures of Alternaria alternata on chrysanthemum (B); Neighbor-Joining distance tree analysis showing the phylogenetic relationships of Alternaria genus. A neighbor-joining tree was performed using ITS rDNA sequences. The sequence of our A. alternata strain is indicated in bold letters. Numbers on branches correspond to bootstrap values obtained with 5,000 replicates (C). 
sent to Macrogen Korea for sequencing in both directions to corroborate the PCR product.

The ITS rDNA sequence generated in this study was deposited in GenBank (National Center for Biotechnology Information) under the accession number MG282916. The ITS sequence of the fungal strain was compared with sequences in Fungal Barcoding for molecular identification.

To analyze the isolated Alternaria strain, 18 accessions of the ITS rDNA sequences were selected and retrieved from the GenBank database representing species within the Alternaria genus. The obtained nucleotide sequence consists of approximately $600 \mathrm{bp}$ which correspond to the ITS rDNA. A sequence of Stemphylium herbarum (KC584239) was used as outgroup. DNA sequences were aligned and a Neighborjoining genetic distance tree was constructed with Geneious software, version 8.1.8 $(3,4)$. Support for specific clades represented in the tree was estimated by Bootstrap analysis of 5,000 replicates. Phylogenetic data were submitted to TreeBase under the submission number S21750 (Fig. 1C).

Pathogenicity tests consisted in applying two treatments (with and without injuries) of 4 replicates, using the method of loose-leaves in sterile plastic boxes and damp paper as substrate. The incubation process was conducted under controlled laboratory conditions in lighting chambers.

The mycelium of Alternaria strain No. 5 grew immersed in the substrate or partially covered; the hyphae were colorless when young but turned brown as they grew. The conidiophores were straight or flexuous, septate, variable in length, between $22.4-72.8 \mu \mathrm{m}$, and brown. In general, conidia were obpiriformis, brown, longitudinal and cross-cutting (Fig. 1B). Each conidium had a short slightly clearer and swollen beak, with a black scar. The conidia exhibited remarkable constrictions in the septa and grew in isolates forming medium-sized chains over the conidiophore. Its size varied. The length of the conidial body was between $8.4 \mu \mathrm{m}$ and $19.6 \mu \mathrm{m}$, meanwhile the length of the beak varied between 0 and $6.67 \mu \mathrm{m}$. The width of the conidium was $4.2-8.4 \mu \mathrm{m}$. The number of transversal septs was between 1 and 7 , with fewer longitudinal and oblique septs. These features of the fungus coincided with the features of A. alternata species described by Ellis (2).

Alternaria isolate M5 sequence was analyzed and compared to the fungal sequences available in molecular databases. The analyzed sequence blasted with sequences of different isolates of Alternaria alternata in the curated molecular database of Fungal Barcoding, showing $100 \%$ similarity.

According to morphological exams, the fungi causing blight symptoms in chrysanthemum plants resulted similar to A. alternata, which was confirmed with molecular studies.

\section{REFERENCES}

1. Cabrera, M.G.; Álvarez, R.E.; Sosa de Castro, N.T.; Sosa López, A. Patógenos de Chrysanthemum sp. en cultivos de las provincias de Corrientes y Chaco, Argentina. In: Reunión de Comunicaciones Científicas y Tecnológicas, 2004, Corrientes. Anais. Corrientes: UNNE, 2004. A-028.

2. Ellis, M.B. Dematiaceous Hyphomycetes. Kew: Commonwealth Mycological Institute, 1971. 608p.

3. Kearse, M.; Moir, R.; Wilson, A.; Stones-Havas, S.; Cheung, M.; Sturrock, S.; Buxton, S.; Cooper, A.; Markowitz, S.; Duran, C.; Thierer, T.; Ashton, B.; Mentjies, P.; Drummond, A. Geneious Basic: an integrated and extendable desktop software platform for the organization and analysis of sequence data. Bioinformatics, Oxford, England, v.28, p.1647-1649, 2012.

4. Pryor, B.M.; Gilbertson, R.L. Molecular phylogenetic relationships amongst Alternaria species and related fungi based upon analysis of nuclear ITS and $\mathrm{mt}$ SSU rDNA sequences. Mycological Research, Cambridge. v.104, p.1312-1321, 2000. 